\title{
Fabrication of deep-profile Al-doped ZnO one- and two-dimensional lattices as plasmonic elements
}

\author{
Jensen, Flemming; Shkondin, Evgeniy; Takayama, Osamu; Larsen, Pernille Voss; Mar, Mikkel \\ Dysseholm; Malureanu, Radu; Lavrinenko, Andrei
}

\author{
Published in: \\ Proceedings of SPIE \\ Link to article, DOI: \\ $10.1117 / 12.2236820$ \\ Publication date: \\ 2016 \\ Document Version \\ Peer reviewed version \\ Link back to DTU Orbit
}

Citation (APA):

Jensen, F., Shkondin, E., Takayama, O., Larsen, P. V., Mar, M. D., Malureanu, R., \& Lavrinenko, A. (2016). Fabrication of deep-profile Al-doped ZnO one- and two-dimensional lattices as plasmonic elements. In Proceedings of SPIE (Vol. 9921). [99210J] SPIE - International Society for Optical Engineering. https://doi.org/10.1117/12.2236820

\section{General rights}

Copyright and moral rights for the publications made accessible in the public portal are retained by the authors and/or other copyright owners and it is a condition of accessing publications that users recognise and abide by the legal requirements associated with these rights.

- Users may download and print one copy of any publication from the public portal for the purpose of private study or research.

- You may not further distribute the material or use it for any profit-making activity or commercial gain

- You may freely distribute the URL identifying the publication in the public portal 


\title{
Fabrication of deep-profile Al-doped ZnO one- and two-dimensional lattices as plasmonic elements
}

\author{
Flemming Jensen ${ }^{\mathrm{a}}$, Evgeniy Shkondin ${ }^{\mathrm{a}, \mathrm{b}}$, Osamu Takayama ${ }^{\mathrm{b}}$, Pernille V. Larsen ${ }^{\mathrm{a}}$, Mikkel D. Mar ${ }^{\mathrm{a}}$, \\ Radu Malureanu ${ }^{\mathrm{b}}$, and Andrei V. Lavrinenko ${ }^{\mathrm{b}}$ \\ ${ }^{a}$ DTU Danchip, National Center for Micro- and Nanofabrication, Technical University of Denmark, \\ Oersteds Plads, Building 347, Kgs. Lyngby, DK-2800, Denmark \\ ${ }^{b}$ Department of Photonics Engineering, Technical University of Denmark, \\ Oersteds Plads, Building 345 V, Kgs. Lyngby 2800, Denmark
}

\begin{abstract}
In this work, we report on fabrication of deep-profile one- and two-dimensional lattices made from $\mathrm{Al}$-doped $\mathrm{ZnO}$ (AZO). AZO is considered as an alternative plasmonic material having the real part of the permittivity negative in the near infrared range. The exact position of the plasma frequency of AZO is doping concentration dependent, allowing for tuning possibilities. In addition, the thickness of the AZO film also affects its material properties. Physical vapor deposition techniques typically applied for AZO coating do not enable deep profiling of a plasmonic structure. Using the atomic layer deposition technique, a highly conformal deposition method, allows us to fabricate high-aspect ratio structures such as one-dimensional lattices with a period of $400 \mathrm{~nm}$ and size of the lamina of $200 \mathrm{~nm}$ in width and $3 \mu \mathrm{m}$ in depth. Thus, our structures have an aspect ratio of 1:15 and are homogeneous on areas of $2 \mathrm{x} 2 \mathrm{~cm}^{2}$ and more. We also produce two-dimensional arrays of circular nanopillars with similar dimensions. Instead of nanopillars hollow tubes with a wall thickness on demand from $20 \mathrm{~nm}$ up to a complete fill can be fabricated.
\end{abstract}

Keywords: AZO; plasmonic material; high aspect ratio lattices; surface waves; atomic layer deposition

\section{INTRODUCTION}

Plasmonics has been an ever-growing subject of research in photonics during the past few decades. It has numerous applications ranging from subwavelength optical devices and spasers to chemical and bio-sensing. Traditionally, noble metals are considered as plasmonic materials in the visible and telecom ranges, with a plasma frequency being typically in the ultraviolet wavelength range. However, they are hardly applicable in the mid-IR, or even in near-IR, where their dielectric permittivity becomes too negative ${ }^{1}$. The quest for a suitable plasmonic material in the near- and mid-IR, which is of special interest for various applications including, but not limited to, sensing, focusing, and waveguiding ${ }^{1}$ has been open for a while.

Transparent conducting oxides (TCOs) have attracted significant attention as alternative plasmonic materials to conventional metals ${ }^{1-3}$. Many studies focus on aluminum- or gallium- doped zinc oxides ${ }^{4-7}$ or tin-doped indium oxide ${ }^{8,9}$ due to their low loss and metallic behavior in the near infrared. One more advantage of TCOs is the possibility of tuning their permittivity by design through deciding the dopants or the ratio of different components ${ }^{10}$, thus constituting an advantage over metals having fixed permittivity values. By exploring this tuning possibility, plasmonic modulators where the TCOs are the active parts were investigated theoretically ${ }^{11}$ and experimentally ${ }^{12}$.

Originally most of the TCOs were deposited by pulsed layer depositions (PLD). However, recently it has been shown that good control in AZO growth can be achieved using the atomic layer deposition (ALD) technique ${ }^{7,13}$. In this work, we report on fabrication of deeply profiled one- and two-dimensional lattices made from AZO to be exploited as plasmonic structures in the near- and mid-IR ranges. 


\section{FABRICATION OF HIGH ASPECT RATIO STRUCTURES}

Nanoscale realization of one- and two-dimensional (1D/2D) high aspect ratio structures with precisely controlled shape and profile depth is a huge challenge and put heavy demands on the fabrication techniques. In a top-down approach one would normally seek a plasma based reactive ion etching (RIE) technique in combination with a lithographically defined masking layer (soft or hard mask) to define the structures. For deep-profile structures it is essential to achieve an etch process with a proper selectivity towards the masking layer and at the same time keep a high degree of anisotropy during etching. This is a highly non-trivial task for most materials including TCOs.

To circumvent this obstacle, Huang et al. suggested as a general fabrication scheme to combine ALD layer formation of the functional material in a pre-defined template with a subsequent selective removal of the template leaving a negative replica of the template structure in the functional material ${ }^{14}$. ALD is a self-limiting growth method governed by surface reaction of two sequentially precursor exposures forming coatings with monolayer precision. This approach is inherently conformal thus the obtained structures will be the "negative" of the template with a high fidelity towards the template structure. In this way the pattern formation can be defined e.g. by a Si template, using deep reactive ion etching (DRIE) of $\mathrm{Si}$, which is a matured and well established technology for high aspect ratio structures ${ }^{15}$. Still, finding a proper selective etch for the Si template removal remains an issue.

In the present work, we have adapted the fabrication scheme of Huang et al. to our material platforms. Figure 1 (a)-(d) illustrates the individual process steps. In the first step (a) a Si template is defined by DRIE in a carefully optimized process in order to obtain trenches with straight sidewalls and the required etch depth. Next, the trench structure is coated using ALD for conformal layer growth (b). This is followed by a top layer removal step whereby the Si template core between the ALD layers is exposed (c) and finally the Si core is removed by a selective Si etch (d).

Figure 1 (e)-(h) shows an example of how this scheme can be applied for realizing a $1 \mathrm{D}$ trench structure in $\mathrm{TiO}_{2}$. In this case the trench pattern for the Si template was defined by deep UV lithography (DUV stepper: Canon FPA-3000 EX4) followed by DRIE etching (DRIE-Pegasus from SPTS) in a switched (Bosch) process consisting of cyclic steps of etching and surface passivation. The processing temperature was kept at $0^{\circ} \mathrm{C}$ and the process pressure at $10 \mathrm{mTorr}$.

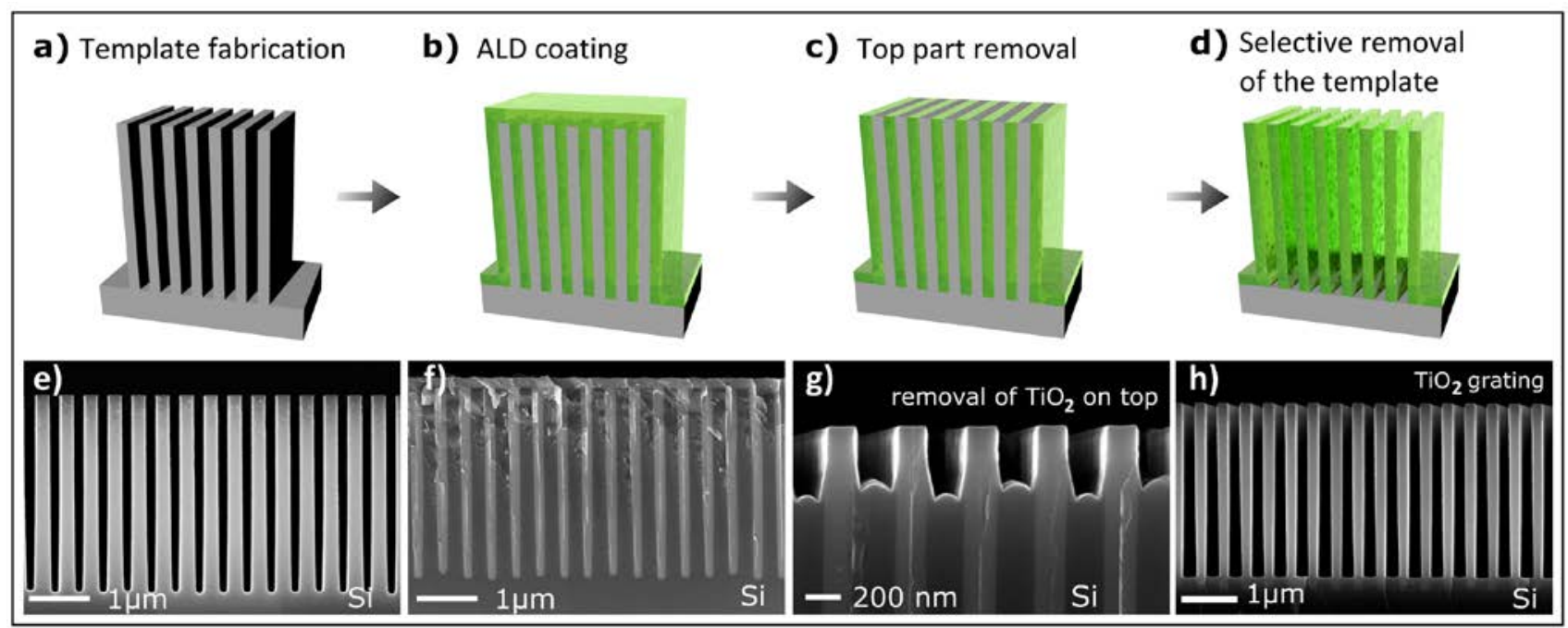

Figure 1. Fabrication flow: (a/e) DRIE template, (b/f) $\mathrm{TiO}_{2}$ ALD deposition, (c/g) top part removal by $\mathrm{Cl}_{2}$ ICP etching for 17 $\mathrm{min},(\mathrm{d} / \mathrm{h}) \mathrm{SF}_{6}$ ICP etching (isotropic $\mathrm{Si}$ etch) leaving the $\mathrm{TiO}_{2}$ grating. (e)-(h) are cross-section SEM micrographs.

Following the template fabrication, conformal ALD layer growth was conducted using a hot wall thermal ALD system (Picosun R200). Here, the $\mathrm{TiO}_{2}$ layer was deposited at $150^{\circ} \mathrm{C}$ using $\mathrm{TiCl}_{4}$ and deionized water (DIW, $\mathrm{H}_{2} \mathrm{O}$ ) as the precursors (both from Sigma-Aldrich). At higher temperatures, the crystalline anatase phase transition would take over and increase the surface roughness ${ }^{16}$. Therefore, to keep the amorphous phase, the deposition was done at or below $150^{\circ} \mathrm{C}$. The number of cycles (2500) was chosen to achieve the desired thickness of approx. $100 \mathrm{~nm} \mathrm{TiO}_{2} \mathrm{coating}$ in 
order to entirely fill the DRIE silicon template. The top $\mathrm{TiO}_{2}$ layer was removed using a $\mathrm{Cl}_{2}$ based inductively coupled plasma etching (Multiplex ICP Etcher from SPTS). It is important that the top layer etch is strictly monitored, since overetching will result in a prominent attack of the $\mathrm{Si}$ core below it. Then, the exposed Si core of the template was removed (etched) using a continuous ICP etching process based on $\mathrm{SF}_{6}$. The chemistry for this Si etch was chosen to ensure high selectivity with respect to the $\mathrm{TiO}_{2}$ ALD coating. As such, we observed no indications of $\mathrm{TiO}_{2}$ degradation during this step. We would like to note that the Si etch is nonlinear in time as the etch rate is reduced with the etch depth. This fact is the reason why the $\mathrm{TiO}_{2}$ removal in the previous step needs to be strictly controlled since an overetching will result in an unknown $\mathrm{Si}$ core height. Thereby the subsequent core removal by $\mathrm{SF}_{6} \mathrm{ICP}$ etching is prone to cause a collapse of the grating structures by underetching the $\mathrm{TiO}_{2}$ grid as the bottom of the trench structure is reached. A slight overetch of silicon during the $\mathrm{TiO}_{2}$ removal step can be seen in Figure 1g. In the shown example the $\mathrm{TiO}_{2}$ grating consists of lamellas with a pitch of $400 \mathrm{~nm}$, a thickness of $200 \mathrm{~nm}$ and a height of $3 \mu \mathrm{m}$ thus having an aspect ratio of 1:15 of the fabricated trench structure. A detailed description of the applied process parameters can be found in ${ }^{17}$.

The fabrication scheme can be extended to multilayer structures as shown in the SEM cross section micrographs in figure 2. Here, the potential of the high conformity growth of the ALD layers is clearly illustrated e.g. for realizing superlattices (see insets (a) and (b) showing magnification of the top- and bottom part, respectively). In this case the Si template formation with a trench depth of $4 \mu \mathrm{m}$ was followed by sequential growth of $\mathrm{Al}_{2} \mathrm{O}_{3}$ ( 3 bright layers) and TiO (2 dark layers), respectively, each with a layer thickness of $30 \mathrm{~nm}$. However, due to slightly negative tapered sidewalls in the $\mathrm{Si}$ template the second $\mathrm{Al}_{2} \mathrm{O}_{3}$ layer closed the top part of the trench (inset (a)) before the second $\mathrm{TiO}_{2}$ deposition was initiated thus blocking for further deposition in the trench structure. This example emphasizes the importance of controlling the straightness of the sidewalls throughout the whole depth of the trench profile.

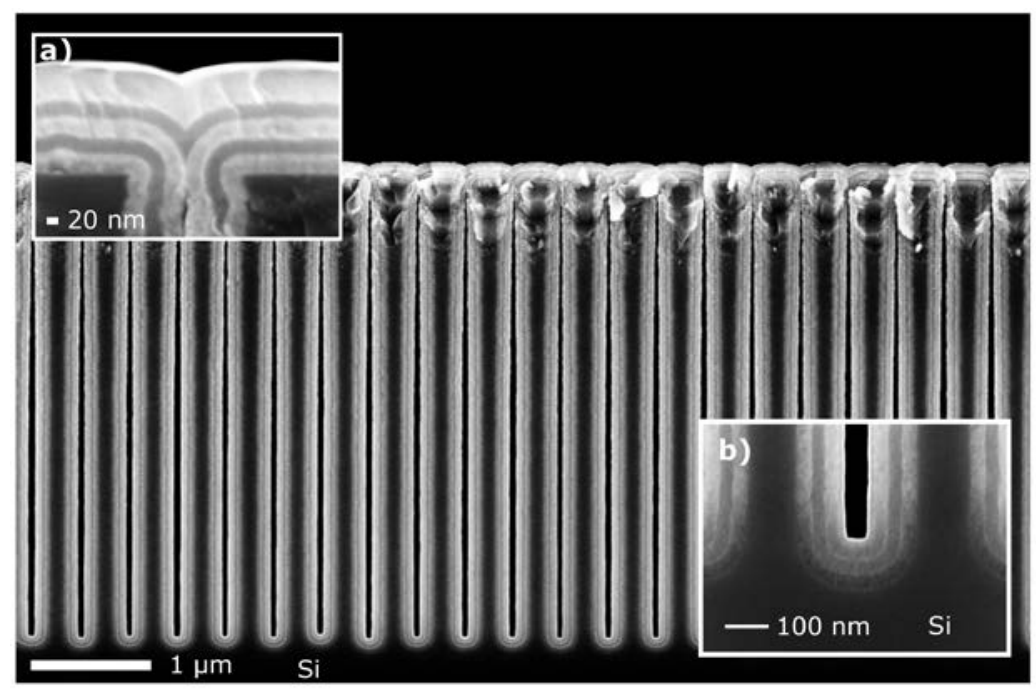

Figure 2. $\mathrm{Al}_{2} \mathrm{O}_{3} / \mathrm{TiO}_{2}$ multilayers deposited on a Si DRIE template grating (each ALD layer is approx. $30 \mathrm{~nm}$ thick). Dark layers are $\mathrm{TiO}_{2}$, bright ones are $\mathrm{Al}_{2} \mathrm{O}_{3}$. Insets show (a) Top part magnification, and (b) Bottom part magnification.

\section{AZO: DEPOSITION SCHEME AND MATERIAL PROPERTIES}

In the pursue of new plasmonic materials for replacing the noble metals, doped oxide semiconductors such as TCOs have attracted substantial attention in recent years. Among these AZO deposited by PLD has shown very promising results as a plasmonic component for a hyperbolic metamaterial in the near-IR region ${ }^{5}$. Following the fabrication scheme described in the previous section, we have applied and optimized ALD for the AZO deposition in the pre-structured Si template.

Prior to the deposition in the Si templates the ALD process was investigated on planar Si(100) substrates for determining the growth rates (not shown here), chemical composition, and film morphology. The details of this study will be 
published elsewhere. In short, a thorough investigation of various dopant concentrations of the AZO was conducted. In this study, a hot wall thermal ALD system (Picosun R200) was used and the precursors were obtained from Strem Chemicals. ZnO ALD was deposited using diethylzinc (DEZ, $\left.\mathrm{Zn}\left(\mathrm{C}_{2} \mathrm{H}_{5}\right)_{2}\right)$ and deionized water (DIW, $\left.\mathrm{H}_{2} \mathrm{O}\right)$ as precursors, whereas $\mathrm{Al}_{2} \mathrm{O}_{3}$ was deposited using trimethylaluminum (TMA, Al( $\left.\left(\mathrm{CH}_{3}\right)_{3}\right)$ and DIW. The Al-doping of the $\mathrm{ZnO}$ was made by introducing a single cycle of (TMA+DIW) into the ZnO matrix made by " $\mathrm{n}$ " (DEZ+DIW) cycles. " $\mathrm{n}$ " was varied between 5 and 35, so each AZO sample was nominated by the certain Al doping level: D05, D10,.., D35. While the dopant concentration was varied, the total film thickness was kept constant at approx. $100 \mathrm{~nm}$.

Selected results from the characterization of the grown AZO D15 films are shown in figure 3 which are examples of (a) an x-ray photoelectron spectroscopy (XPS) measurement revealing the chemical composition and (b) a SEM image (inset in (b) is an atomic force microscopy scan of the surface) showing the surface morphology. XPS chemical trace analysis (performed using Thermo Avantage v5.948 software from Thermo Scientific) revealed a high quality chemical film with no observable impurities. The Al concentration in D15 doped AZO film was found to be 12.8 At. \%. Prior to the XPS measurements the film surface was sputtered in-situ with Ar+ ions in order to get rid of the native airborne hydrocarbons.

The surface morphology is found to be dependent on growth temperature and doping level. In general, the higher the Al doping level, the smoother the surface. However, a minimum of 4-6 (DEZ+DIW) cycles are required for stable nucleation of the $\mathrm{ZnO}$ layer on $\mathrm{Al}_{2} \mathrm{O}_{3}$ setting an upper limit for the $\mathrm{Al}$ doping concentration (around D05). For the AZO D15 films we find a relative smooth surface with a roughness of approx. $2.35 \mathrm{~nm}$ RMS. These findings are in agreement with previously reported results ${ }^{19}$.

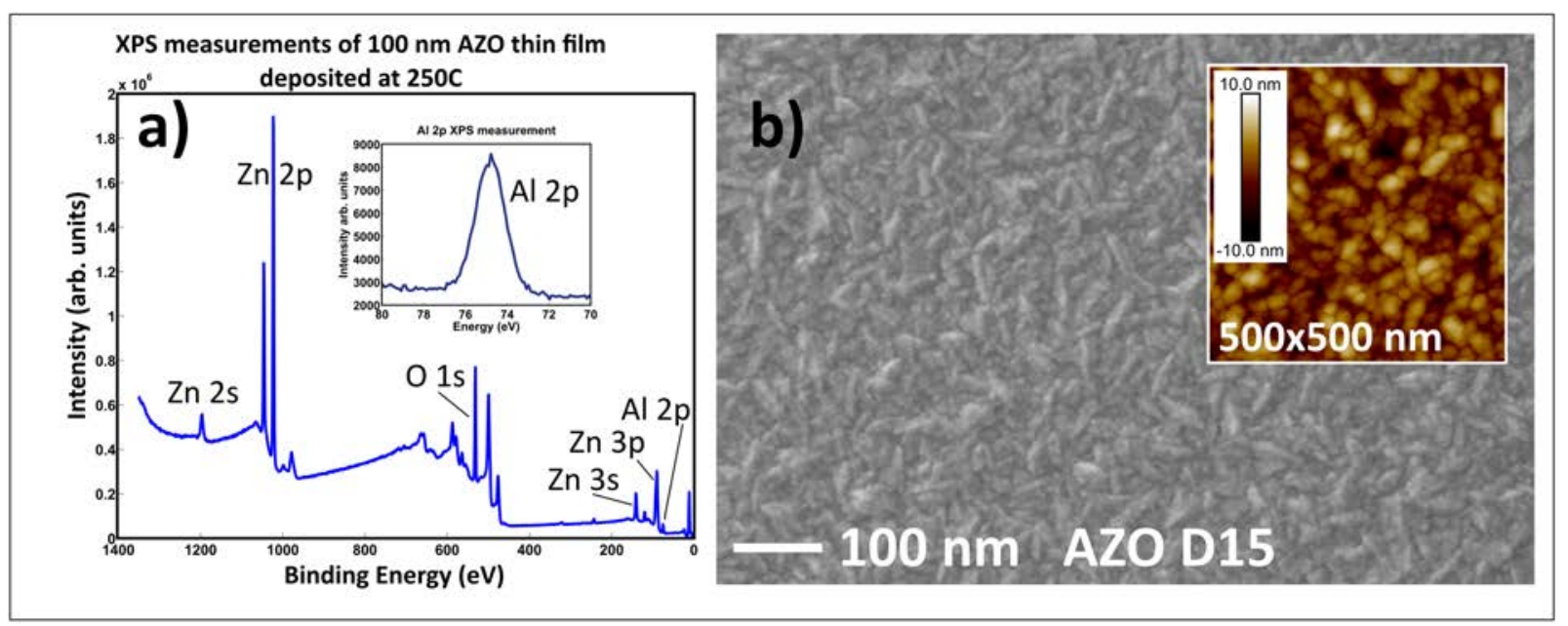

Figure 3. AZO material properties: (a) XPS survey scan of AZO D15 grown at $250{ }^{\circ} \mathrm{C}, 100 \mathrm{~nm}$ thin film. The inset is a high resolution $\mathrm{Al}$ 2p scan, (b) SEM image of the AZO film surface and an AFM scan (inset).

Regarding the optical properties of the AZO films spectroscopic ellipsometry data were collected using a VASE Ellipsometer from J.A. Woollam Co. In spectroscopic ellipsometry the parameters $\psi$ and $\Delta$ are measured over a certain wavelength range (this case $210-1690 \mathrm{~nm}$ ) where $\psi$ and $\Delta$ are defined by $r_{p} / r_{s}=\tan (\psi) \cdot e^{i \Delta}$, where

$r_{p}$ and $r_{s}$ are the reflection coefficients of $\mathrm{p}$ and s polarized light. The experimentally obtained values of $\psi$ and $\Delta$ were fitted using Kramers-Kronig relations. Figure 4 shows an example of the optical permittivity measurements obtained as a function of wavelength in the range of $210-1690 \mathrm{~nm}$. In figure 4 both the real- $\left(\varepsilon_{1}\right)$ and imaginary $\left(\varepsilon_{2}\right)$ part of the dielectric function are displayed. For comparison, the permittivity was measured both for AZO D15 and undoped ZnO films each having a film thickness of $100 \mathrm{~nm}$. 


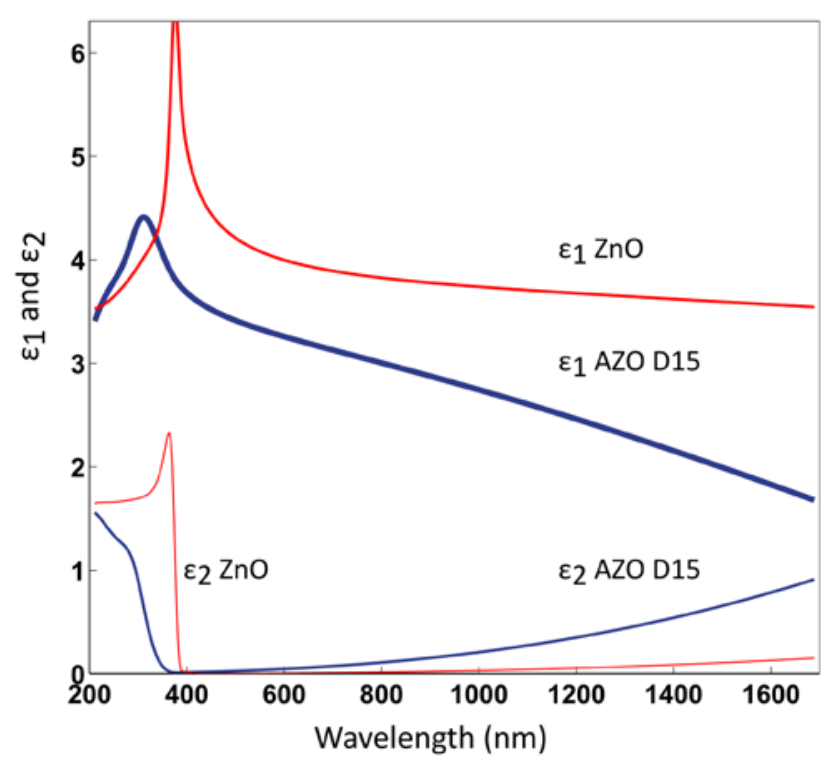

Figure 4. AZO material optical properties. Permittivity's real $\left(\varepsilon_{1}\right)$ and imaginary $\left(\varepsilon_{2}\right)$ parts for AZO D15 (blue) and undoped $\mathrm{ZnO}$ (red) obtained by spectroscopic ellipsometry.

Fitting these data with a Drude model we can estimate that the real part of permittivity of AZO D15 approaches zero at a wavelength of approx. $2.5 \mu \mathrm{m}$, in good agreement with recent studies ${ }^{20,21}$.

\section{FABRICATION OF AZO 1D- AND 2D-STRUCTURES}

The next step was to apply the high aspect ratio fabrication scheme described above on the AZO material platform to form $1 \mathrm{D}$ - and 2D-structures. In the case of $1 \mathrm{D}$ grating structures, we found that the scheme described in section 2 (see figure 1(a)-(d)) works very well for the AZO with minor modifications. Step 1 and 2 (figure 1(a) and (b)) were the same except for the ALD layer material (now AZO). For the top layer removal a pure physical etching step was used by applying an $\mathrm{Ar}^{+}$ion sputter etching (Ionfab 300 Plus from Oxford Instruments). Here, the process was tuned to an etch rate of $20 \mathrm{~nm} / \mathrm{min}$ which provided a well-controlled top layer breakthrough. Following this, the exposed Si core could be removed selectively by an isotropic $\mathrm{SF}_{6}$ based RIE process without any noticeable influence of the AZO layer quality (very high selectivity).

It should be noted that the structure height is determined by the initial trench height of the Si template and therefore in this case depends on the Si etch rate and time applied in step 1 (figure 1(a)). As the etch rate vary with etch depth or depends on the aspect ratio of the structure to be defined (aspect ratio dependent etching - $\mathrm{ARDE}^{22}$ ) it can be a major advantage to control the structure height by a built-in etch stop. This can be achieved by using a silicon-on-insulator (SOI) wafer with a buried $\mathrm{SiO}_{2}$ layer as starting material and a device layer thickness corresponding to the wanted structure height. This ensures full control of the trench height in the formation of the Si template as the DRIE step can be designed to stop at the buried $\mathrm{SiO}_{2}$ layer.

In the present study for the fabrication of 2D structures (nanopillars, figure 5), home-made SOI wafers were manufactured by growing an amorphous Si layer using low pressure chemical vapor deposition (LPCVD) on top of an oxidized $\mathrm{Si}(100)$ wafer. First, standard $\mathrm{Si}(100)$ wafers were oxidized in a conventional quartz tube furnace (from Tempress) using a dry oxidation process based on $\mathrm{O}_{2}$ at $1100^{\circ} \mathrm{C}$, resulting in a $200 \mathrm{~nm} \mathrm{SiO}_{2}$ on Si. Next, a $1 \mu \mathrm{m}$ amorphous Si layer was grown on the $\mathrm{SiO}_{2}$ surface using a conventional LPCVD process (LPCVD furnace from 
Tempress) based on $\mathrm{SiH}_{4}$ at $560^{\circ} \mathrm{C}$. The surface roughness is below $1 \mathrm{~nm}$, thus of sufficient quality to be used as base material for the Si template. Figure 5 shows the final result of the fabricated 2-dimensional arrays of circular AZO D25 nanopillars. These pillars have a diameter of $250 \mathrm{~nm}$, a height of $1 \mu \mathrm{m}$ and a pitch of $500 \mathrm{~nm}$.

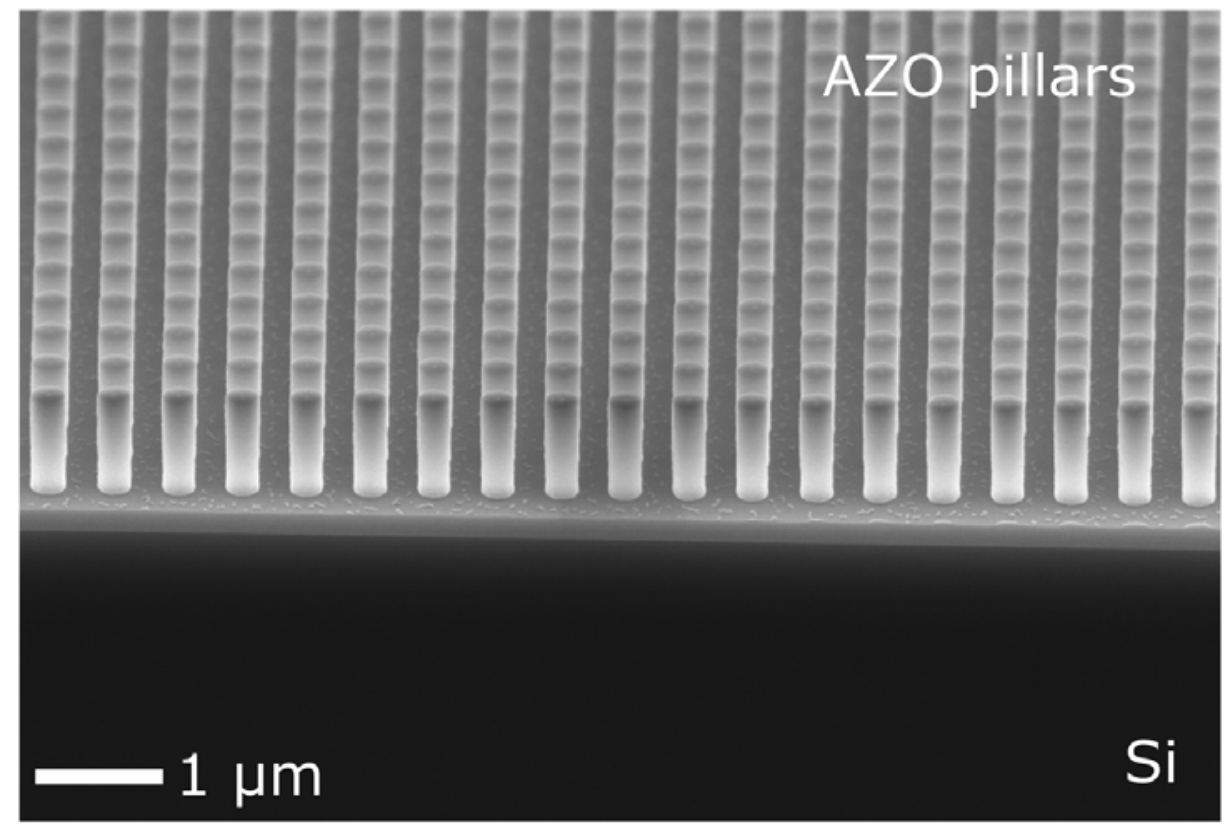

Figure 5. Example (SEM micrographs) of 2D deep-profile AZO array of circular nanopillars.

\section{CONCLUSION}

To summarize, transparent conductive oxides offer new promising opportunities compared to the noble metals as plasmonic materials in the mid- and near-infrared due to the low loss metallic behavior in this region and the possibility of tuning the permittivity. However, to exploit the various applications in optical devices it is essential to develop techniques for structuring these materials at nanoscale. We present a new scheme for fabricating well-controlled deepprofile 1- and 2-D nanoscale structures in AZO and other oxides. The examples presented in the present work illustrate the huge potential of this technique as a highly versatile and generic fabrication scheme for a large variety of materials and structural elements. With the inherent accuracy and scalability of the lithography- and etching tools applied, it is possible to realize large coherent areas of nanostructural elements on a $150 \mathrm{~mm}$ wafer (step-and-repeat of printed field sizes of $22 \times 26 \mathrm{~mm}^{2}$ for the DUV stepper) with feature sizes down to ca. $200 \mathrm{~nm}$. Thus, the full potential of mass production of nanostructural elements in new material platforms (and combinations of these) such as TCO materials for plasmonic structures is opened for advanced metamaterials fabrication.

\section{REFERENCES}

[1] Naik, G. V., Shalaev, V. M., and Boltasseva, A., "Alternative plasmonic materials: beyond gold and silver," Adv. Mater. 25, 3264-3294 (2013).

[2] Naik, G. V., Kim, J., and Boltasseva, A., "Oxides and nitrides as alternative plasmonic materials in the optical range," Opt. Mater. Express 1, 1090-1099 (2011). 
[3] Noginov M. A., Gu L., Livenere J., Zhu G., Pradhan A. K., Mundle R., Bahoura M., Barnakov Y. A., Podolskiy V. A., “Transparent conductive oxides: plasmonic materials for telecom wavelengths,” Appl. Phys. Lett. 99, 21101 (2011).

[4] Kim, J. S., Jeong, J.-H., Park, J. K., Baik, Y. J., Kim, I. H., Seong, T.-Y., and Kim, W. M., "Optical analysis of doped ZnO thin films using nonparabolic conduction-band parameters," J. Appl. Phys. 111, 123507 (2012).

[5] Naik, G. V., Liu, J., Kildishev, A. V., Shalaev, V. M., and Boltasseva, A., "Demonstration of Al:ZnO as a plasmonic component for near-infrared metamaterials," Proc. Natl. Acad. Sci. USA 109, 8834-8838 (2012).

[6] Kim, J., Naik, G. V., Gavrilenko, A. V., Dondapati, K., Gavrilenko, V. I., Prokes, S. M., Glembocki, O. J., Shalaev, V. M., and Boltasseva, A., "Optical Properties of Gallium-Doped Zinc Oxide-A Low-Loss Plasmonic Material: First-Principles Theory and Experiment," Phys. Rev. X 3, 041037 (2013).

[7] Frölich, A. and Wegener, M., "Spectroscopic characterization of highly doped ZnO films grown by atomic-layer deposition for three-dimensional infrared metamaterials,” Opt. Mater.Express 1, 883-889 (2011).

[8] Wang, T., Zalkovskij, M., Iwaszczuk, K., Lavrinenko, A. V., Naik, G. V., Kim, J., Boltasseva, A., and Jepsen, P. U., "Ultrabroadband terahertz conductivity of highly doped ZnO and ITO,” Optical Materials Express v.5, No.3, p.566-575 (2015).

[9] Chen, C.-W., Lin, Y.-C., Chang, C.-H., Yu, P., Shieh, J.-M., and Pan, C.-L., "Frequency-Dependent Complex Conductivities and Dielectric Responses of Indium Tin Oxide Thin Films from the Visible to the Far-Infrared," IEEE J. Quantum Electron 46, 1746-1754 (2010).

[10] Mishra, S. K. and Gupta, B. D., "Surface plasmon resonance-based fiber-optic hydrogen gas sensor utilizing indium-tin oxide (ITO) thin films,” Plasmonics 7, 627-632 (2012).

[11] Babicheva, V. E., Kinsey, N., Naik, G. V., Ferrera, M., Lavrinenko A. V., Shalaev, V. M., and Boltasseva, A., "Towards CMOS-compatible nanophotonics: ultra-compact modulators using alternative plasmonic materials," Opt. Express 21, 27326-27337 (2013).

[12] Melikyan, A., Lindenmann, N., Walheim, S., Leufke, P. M., Ulrich, S., Ye, J., Vincze, P., Hahn, H., Schimmel, T., Koos, C., Freude, W., and Leuthold, J., “Surface plasmon polariton absorption modulator,” Opt. Express 19, 8855-8869 (2011).

[13] Riley, C. T., Smalley, J. S. T., Post, K. W., Basov, D. N., Fainman, Y., Wang, D., Liu, Z., and Sirbuly, D. J., "High-Quality, Ultraconformal Aluminum-Doped Zinc Oxide Nanoplasmonic and Hyperbolic Metamaterials," Small 12, No. 7, 892-901 (2016).

[14] Huang, Y., Pandraud, G., and Sarro, P. M., "The atomic layer deposition array defined by etch-back technique: a new method to fabricate $\mathrm{TiO}_{2}$ nanopillars, nanotubes and nanochannel arrays,” Nanotechnology 23, 485306 (2012).

[15] Jansen, H. V., de Boer, M. J., Unnikrishnan, S., Louwerse, M. C., and Elwenspoek, M. C., "Black silicon method: X. A review on high speed and selective plasma etching of silicon with profile control: an in-depth comparison between Bosch and cryostat DRIE processes as a roadmap to next generation equipment,” J. Micromechanics Microengineering 19, 033001 (2009).

[16] Lee, W. J. and Hon, M. H., "Space-Limited Crystal Growth Mechanism of $\mathrm{TiO}_{2}$ Films by Atomic Layer deposition,” J. Phys. Chem. 114, 6917-6921 (2010).

[17] Shkondin, E., Takayama, O., Lindhard, J. L., Larsen, P. V., Mar, M. D., Jensen, F., and Lavrinenko, A., "Fabrication of high aspect ratio $\mathrm{TiO}_{2}$ and $\mathrm{Al}_{2} \mathrm{O}_{3}$ nanogratings by atomic layer deposition,” J. Vac. Sci. Technol. A34, 031605 (2016).

[18] Elam, J. W. and George, S. M., "Growth of $\mathrm{ZnO} / \mathrm{Al}_{2} \mathrm{O}_{3}$ alloy films using atomic layer deposition techniques," Chem. Mater. 15, 1020 (2003).

[19] Dhakal, T., Vanhart, D., Christian, R., Nandur, A., Sharma, A., and Westgate, C., "Growth morphology and electrical/optical properties of Al-doped $\mathrm{ZnO}$ thin films grown by atomic layer deposition,” J. Vac. Sci. technol. A 30, 021202 (2012).

[20] Latzel, M., Göbelt, M., Brönstrup, G., Venzago, C., Schmitt, S. W., Sarau, G., and Christiansen, S. H., "Modelling the dielectric function of degenerately doped ZnO:Al thin films grown by ALD using physical parameters,” Opt. Mater. Express 5, 241793 (2015).

[21] Kelly, P., Liu, M., and Kuznetsova, L., "Designing optical metamaterials with hyperbolic dispersion based on an $\mathrm{Al}: \mathrm{ZnO} / \mathrm{ZnO}$ nano-layered structure using atomic layer deposition technique,” Appl. Optics 55, 2993-2997 (2016).

[22] Lai, S. L., Johnson, D., and Westerman, R., “Aspect ratio dependent etching lag reduction in deep silicon etch processes,” J. Vac. Sci. Technol. A24, 1283 (2006). 